\title{
Analysis of Vitiligo Model Based on Clinical Features of Traditional Chinese Medicine and Western Medicine
}

\author{
Xiao-li YAN, Li-hua CAO and Ming-san MIAO* \\ Henan University of traditional Chinese Medicine in Henan
}

${ }^{*}$ Corresponding author

Keywords: Vitiligo, Clinical disease, Animal model.

\begin{abstract}
Objective: Analysis common animal models and vitiligo clinical symptoms anastomotic situation, put forward recommendations of improving the model. Methods: By summarizing the characteristics and modeling methods of vitiligo model and according to the clinical diagnostic criteria of vitiligo on TCM and Western Medicine, analysised animal models and vitiligo clinical symptoms anastomotic situation, then put forward the evaluation index system and model improvement method of vitiligo model. Results: Nowadays, most of the vitiligo models were based on a pathological animal model caused by abnormal melanin synthesis, according to the existing theory, the preparation method was mainly chemical decolorization method (hydroquinone, hydrogen peroxide method and monochromycin cream decolorization method).Conclusion: We should establish quantitative evaluation method of vitiligo, improve the existing model thinking.
\end{abstract}

\section{Introduction}

Vitiligo is a common clinical skin pigmentation disorders and acquired pigment loss of skin disease, incidence rate of world about $0.5 \%$ to $1 \%$ [1], the incidence of young people is more high .It is a disease which is easy to diagnose but difficult to cure and affect the appearance of the patient. Vitiligo in Chinese medicine called "vitiligo""baibofeng" and "white barge" and "white" and Chinese medicine believes that the cause of suffering from vitiligo patients is mostly Yin, liver qi stagnation, or feeling six exopathogens, resulting in disharmony of qi and blood which cannot nourish skin.Modern medicine believes that vitiligo is a skin disease characterized by localized or generalized depigmentation of the skin due to a decrease in the function of the tyrosinase system in melanocytes. So far the Vitiligo models are mostly pathological animal models, but also having the animal models design in the light of some specific symptoms.

\section{Western Medicine Diagnosis of Vitiligo and Clinical Manifestations Diagnostic Criteria}

Based on the characteristics of vitiligo animal model analysis, the model is mainly to reflect the characteristics of Western animal model, with reference to the 2002 Southeast University Press Zhu Wenyuan editor of "vitiligo and chloasma" [3] to develop the diagnostic criteria for vitiligo: IIAcquired depigmentation spots or hypopigmentation spots. (2)Skin lesions are clear and irregular shape; (3)skin lesions deepening in the edge; mlesions within the hair can be white or visible hair follicle around the phenomenon of complex color; $\Omega$ Under the W00d lamp is white porcelain white. The first of the 5 items is the necessary condition and there are three established can be diagnosed as vitiligo. 


\section{Clinical Manifestations}

Referring to the revised<clinical classification and curative effect standard of vitiligo> by pigmented group in China Association of traditional Chinese and Western medicine dermatology Specialized Committee. The clinical classification of vitiligo is mainly: (1) unusual type: limited type: single or multiple white spots, confined to a certain area, white area accounted for body surface area $\leq 10 \%$. Dispersion type: scattered, multiple white spots, often symmetrical distribution, $10 \%$ <white area accounted for body surface area of hair $\leq 50 \%$. General hair type: more from the development of distributed, white and more into each other irregular large, sometimes only small pieces of island-like normal skin color, white area accounted for body surface area $>50 \%$. Acromegaly: white spots originated in the body's acral and / or facial, and mainly distributed in these parts. (2) Segment type: white spot is one or several pieces, along a certain skin nerve segment dominated the skin area to the distribution, generally unilateral. Clinical stage for the progress: white spots increased, the original white gradually migrate to the normal skin, expand, the state blurred, prone to homotypic reaction. Stable: white stop to develop, the state clear, white edge of the pigment deepened, no new white spots appear.

\section{Observe Indicators}

1.3.1 Apparent indicators The Apparent indicators of the clinical vitiligo patients white spot type (localized, disseminated, pan-type, skin-end type, segment type)are observed mainly from duration of disease, progress, white color, shape and border conditions .

1.3.2 Biochemical parameters: The Biochemical parameters are measured mainly from clinical vitiligo patients serum tyrosine (TYR) content, cholinesterase (ChE) activity, monoamine oxidase (MAO) content, malondialdehyde (MDA) content, IL-6 content, TNF $-\alpha$ content.

1.3.3 Pathological indicators: Determination of vitiligo patients with skin area on the number of melanoma hair follicle and melanin particles in the number of cells.

\section{Chinese Medicine Diagnostic Criteria and Clinical Manifestations of Vitiligo}

\section{Diagnostic Criteria}

Ancient Chinese physicians believe that vitiligo involving lung, heart, spleen, liver and other organs, and the wind, heat, outside the wet, gas, blood, the disease is located in the skin, the main pathogenic wind attack, Or qi stagnation [4]. According to the white spot type (localized, sporadic, generalized, skin type, segment type) course of disease length, progress, white color, shape, border, whether mental factors or family history, combined with Chinese medicine syndromes and Syndrome performance to determine the classification of Chinese medicine vitiligo.

\section{Clinical Manifestations}

Chinese medicine believes that vitiligo always caused by blood loss, contextual resistance caused by resistance. Feelings of internal injuries, liver qi stagnation, poor air, complex wind evil, stroke in the skin; prime liver and kidney weakness, or death fine blood loss, liver and kidney injury, liver and kidney deficiency, exorcism invasion, Yu in the skin; Bruises, chemical burns, collaterals, hairache occlusion, skin care and care, lead to white spots. Based on the theory of ancient physicians, based on the discussion of the disease, to further elaborate its etiology and pathogenesis, the main summary summarized as shown in Table 1 . 
Table 1 vitiligo syndrome differentiation of traditional Chinese medicine

\begin{tabular}{|l|l|l|l|}
\hline Classification & Main symptoms & Secondary symptoms & Tongue and pulse \\
\hline $\begin{array}{l}\text { Qi and blood } \\
\text { lose balance }\end{array}$ & $\begin{array}{l}\text { Short course of disease,rapid } \\
\text { development,often single or } \\
\text { distributed, white pale or } \\
\text { pink, round or irregular } \\
\text { shape, the border is unclear, } \\
\text { skin lesions with rash and } \\
\text { other symptoms. }\end{array}$ & $\begin{array}{l}\text { Often with physical } \\
\text { weakness, before the } \\
\text { onset with physical } \\
\text { weakness. }\end{array}$ & $\begin{array}{l}\text { Pale or pale pink, } \\
\text { white fur, pulse } \\
\text { floating, or weak, } \\
\text { or chord. }\end{array}$ \\
\hline $\begin{array}{l}\text { Liver and } \\
\text { kidney } \\
\text { ceficiency } \\
\text { certificate[5] }\end{array}$ & $\begin{array}{l}\text { Long course of disease, often } \\
\text { genetic history, white spot in } \\
\text { a stable period, can be } \\
\text { generalized or } \\
\text { distributed,white porcelain } \\
\text { white, clear boundaries, spot } \\
\text { hair white }\end{array}$ & $\begin{array}{l}\text { Often accompanied by } \\
\text { Yaoxisuanruan, } \\
\text { dizziness, tinnitus, two } \\
\text { eyes dry. }\end{array}$ & $\begin{array}{l}\text { Pale tongue, less } \\
\text { moss, thin pulse. }\end{array}$ \\
\hline $\begin{array}{l}\text { Blood stasis } \\
\text { syndrome }\end{array}$ & $\begin{array}{l}\text { The course of disease is long, } \\
\text { the development is slow, } \\
\text { single, sporadic or segmental } \\
\text { distribution, white spot } \\
\text { porcelain white, the middle of } \\
\text { the colored Island, the spot } \\
\text { hair variable white, clear } \\
\text { boundary, the edge of colored } \\
\text { sink }\end{array}$ & $\begin{array}{l}\text { Often accompanied by } \\
\text { emotional depression or } \\
\text { irritability, chest pain, } \\
\text { women can be } \\
\text { accompanied by } \\
\text { irregular menstruation. }\end{array}$ & $\begin{array}{l}\text { Dark tongue or } \\
\text { petechiae, moss } \\
\text { white or yellow, } \\
\text { thin, wiry or } \\
\text { astringent. }\end{array}$ \\
\hline $\begin{array}{l}\text { Damp heat } \\
\text { connotation } \\
\text { certificate }\end{array}$ & $\begin{array}{l}\text { Rapid disease } \\
\text { development,often sporadic } \\
\text { or generalized,white or pale } \\
\text { pink, }\end{array}$ & $\begin{array}{l}\text { Withing abdominal } \\
\text { fullness and oppression } \\
\text { bitter taste, yellow } \\
\text { urine, hot body easy to } \\
\text { sweat. }\end{array}$ & $\begin{array}{l}\text { Red tongue, } \\
\text { yellow or yellow } \\
\text { slippery pulse } \\
\text { number or } \\
\text { moisten }\end{array}$ \\
\hline
\end{tabular}

\section{Animal Model of Vitiligo}

\section{Selection of Model Animals}

Vitiligo commonly used experimental animals are guinea pigs (black, gray, brown, yellow), C57BL / 6 mice, Smyth line (SL) chickens, rats, vitiligo dogs, cats and horses. The guinea pig model are wildly used in the clinical practice of vitiligo, pathology, genetics, biochemistry and immunology and other aspects .

\subsection{Observe indicators}

\subsubsection{Apparent indicators}

Apparent indicators observes mainly from the pigment, the size of the pigment area, the degree of dry scaling, erythema edema, blister erosion and other aspects. Apparent indicators can be quantified or semi-quantified grade and have four grading. After the success of the model preparation, there is no pigment, and the skin was pale, white, dry with marked desquamation,erythema with obvious edema and blisters with erosion.

\section{Biochemical Indicators}

After the success of the model preparation: Serum tyrosine (TYR) content decreased significantly; cholinesterase (ChE) activity increased; monoamine oxidase (MAO) content increased; malondialdehyde (MDA) content increased; the increase of the content of IL-6, the content of TNF- $\alpha$ increase. 


\section{Pathological Parameters [6]}

After the preparation of the model successfully, thickened spinous layer and the stratum corneum hyperplasia was obvious.After Lillie staining of melanin, the number of melanin hair follicles was significantly decreased $(P \leq 0.01)$. The cells of the basal cell and spine cell granules were observed at high magnification, the number of cells with melanin granules was significantly reduced $(P \leq 0.01)$.

\section{Modeling Method and Its Coincidence with Clinical Symptoms}

Table 2 common vitiligo animal model building methods and in accordance with the characteristics of Chinese and western medicine disease.

\begin{tabular}{|c|c|c|c|}
\hline Modeling method & Modeling object & Mechanism and characteristics & $\begin{array}{l}\text { Clinical coincidence } \\
\text { degree of clinical } \\
\text { disease and } \\
\text { diagnostic criteria }\end{array}$ \\
\hline $\begin{array}{l}\text { Hydroquinone } \\
\text { decoloring } \\
\text { method }\end{array}$ & $\begin{array}{l}\text { Black or dark color } \\
\text { guinea pigs, C57BL } \\
\text { / } 6 \text { mice[8] }\end{array}$ & $\begin{array}{l}\text { The mechanism is to inhibit TYR } \\
\text { catalytic tyrosine into melanin, } \\
\text { TYR is melanin synthesis rate } \\
\text { limiting enzyme. } \\
\text { C57BL/6 mice were used to } \\
\text { study the regulation of } \\
\text { proliferation and differentiation } \\
\text { of hair follicle } \\
\text { melanocytes.Guinea pigs are } \\
\text { often used to study UV induced } \\
\text { pigmentation in treatment of } \\
\text { vitiligo and pharmacodynamic } \\
\text { studies on tyrosinase inhibitors } \\
\text { and sunscreens. }\end{array}$ & $\begin{array}{l}\text { Meet the diagnostic } \\
\text { criteria of Western } \\
\text { Medicine1.1:(1) (2) (4) } \\
\text { 5); } \\
\text { Match degree is } \\
80 \% \text {,Its application is } \\
\text { more common. }\end{array}$ \\
\hline $\begin{array}{l}\text { Hydrogen } \\
\text { peroxide } \\
\text { bleaching method }\end{array}$ & $\begin{array}{l}\text { Black or dark color } \\
\text { guinea pigs[9] }\end{array}$ & $\begin{array}{l}\text { According to the instability of } \\
\text { melanin, susceptible to strong } \\
\text { oxidant hydrogen peroxide } \\
\text { damage characteristics, the use of } \\
5 \% \text { hydrogen peroxide external } \\
\text { make the guinea pig black skin } \\
\text { decolorization. } \\
\text { Features: the same with } \\
\text { hydroquinone }\end{array}$ & $\begin{array}{l}\text { Meet the diagnostic } \\
\text { criteria of Western } \\
\text { Medicine 1.1:(1) (2) (4) } \\
5 \text {; } \\
\text { Match degree is } 80 \% \text {, } \\
\text { applicate more. }\end{array}$ \\
\hline $\begin{array}{l}\text { Monochlorizine } \\
\text { cream } \\
\text { decolorization } \\
\text { method[10] }\end{array}$ & C57BL/6 mice & $\begin{array}{l}\text { Through the tyrosinase and } \\
\text { reactive oxygen free radical } \\
\text { (ROS) interaction to complete, } \\
\text { causing systemic autoimmune } \\
\text { response, and acts on } \\
\text { melanocytes result in } \\
\text { depigmentation } \\
\text { Features: not only in the } \\
\text { medication site decolorization, } \\
\text { and in the non-drug parts appear } \\
\text { obvious bleaching, such as ears } \\
\text { and tail and so on. }\end{array}$ & $\begin{array}{l}\text { Meet the diagnostic } \\
\text { criteria of Western } \\
\text { Medicine 1.1:(1) (2) (4) } \\
5 \text {; } \\
\text { Match degree is } 60 \% \text {, } \\
\text { the application. }\end{array}$ \\
\hline
\end{tabular}

Note: meet the clinical diagnosis of Chinese medicine a standard 20 points. (Western medicine> 70\%): high degree of coincidence (Western medicine $>50 \%,<70 \%$ ): low degree of fit (Chinese medicine $<50 \%$, Western medicine $<50 \%$ ).

Major clinical manifestations of vitiligo is depigmentation of skin defect,which is 
manifested as milk-white, different size, shape, edge state clearly. Modern medicine on the pathogenesis of vitiligo is still not very clear, but studies have shown that with genetic factors, autoimmune, trauma, chemical factors and melanocyte destruction and so on. According to the existing theory model preparation methods mainly for chemical decolorization method (hydroquinone and hydrogen peroxide method). TCM syndrome differentiation and treatment of vitiligo is the most common blood stasis and kidney yin deficiency.Vitiligo model of TCM in accordance with a certain type of TCM syndrome or clinical manifestations of some syndromes and then add hydrogen peroxide or hydroquinone topical animal skin discoloration [7]. Model establishment and clinical coincidence degree are shown in Table 2.

\section{Outlook}

The biggest difference of the existing vitiligo mode lwith other existing animal models is based on the Western diagnostic criteria as the success of the model to determine the standard, commonly used modeling animals are mice and guinea pigs. Throughout the vitiligo animal model developed, the current use of the most is a single factor or chemical modeling method, but Traditional Chinese medicine has a variety of syndrome differentiation for vitiligo etiology, pathology, pathogenesis and clinical manifestations and current modeling methods cannot fully reflect the pathogenesis of vitiligo patients.So we should paid more attention to multi factor composite molding method combined with the pathogenesis of traditional Chinese Medicine.

\section{References}

[1] Nicolaidou E, Antoniou C, Miniati A, et al. Childhood and later onset vitiligo have diverse epidemiologic and clinical characteristics [J]. JAm Acad Dermatol, 2012, 66 ( 6) : 954-958.

[2] Akrem J, Mrabet Y, Mohamed H. Oxidative stress in experimental vitiligo C57B1/6 mice [J]. Indian J Dermatol, 2012, 57(4): 221-224.

[3]Wenyuan Zhu . White paralysis wind and yellow speckle. Nanjing: Southeast University press, 2002 (in Chinese); (1) 125.In Chinese.

[4]Xue Jiang, Qian L, Wenhao Zheng. Comparison of therapeutic effects of different traditional Chinese medicines on guinea pig model of vitiligo [J]. International Journal of laboratory medicine, 2015,36, (18): 2672-2673+2676.In Chinese.

[5] Haiming Yin, Shengcun Li, Renling Wan, dream Fu, Jing Shang, Zhigang Liu. Chinese and Western medicine in the etiology of vitiligo comparative analysis [J]. Liaoning Journal of traditional Chinese medicine, 2017,44 (01): 20-23.In Chinese.

[6]Xiaolan Zhu, Guorong Sheng, Yongme Yangi. [J]. Buguzhi tincture pharmacology and clinical effect of traditional Chinese medicine on experimental vitiligo model, 2014,30 (06): 115-117.In Chinese.

[7]Jianwe Lui,Lu Lu, Shizhong, organ, willow. Animal model to study the progression of vitiligo and thinking of $[\mathrm{J}]$. Hunan Journal of traditional Chinese medicine, 2014,30 (04): 188-190.In Chinese. 
[8]Li Gao, Shixia Huo, Xiaoming Peng,Pingping Zhao, Yan He, Ming Yan . Effect of galangin on the vitiligo mice induced by hydroquinone in the Chinese herbal medicine [J]. 2014, 45 (16): 2358-2363.In Chinese.

[9]Ying Ai ,Guohua Yu . Journal of anti Decoction on experimental vitiligo in guinea pig [J]. Chinese neuroanatomy, 2014,20 (13): 152-156.In Chinese.

[10] Yiping Zhu, Wang Suiquan, Liangjun Lu, Ai-e Xu. Halometasone, Scutellaria extract effects of combination therapy of vitiligo mice [J]. China Pharmacological Bulletin, 2014, 30 (04): 554-558.In Chinese. 